\title{
Interações silício-fósforo em solos cultivados com eucalipto em casa de vegetação(1)
}

\author{
Rui Carvalho(2), Antonio Eduardo Furtini Neto(3), Custódio Donizete dos Santos ${ }^{(2)}$, \\ Luiz Arnaldo Fernandes ${ }^{(4)}$, Nilton Curi( ${ }^{(3)}$ e Daniel de Castro Rodrigues ${ }^{(5)}$
}

\begin{abstract}
Resumo - Este trabalho teve o objetivo de avaliar as interações Si-P em dois solos, por meio do estado nutricional de $\mathrm{P}$ em mudas de Eucalyptus grandis sob efeito de aplicação de Si. Foram conduzidos dois experimentos em casa de vegetação, utilizando como substratos as camadas superficiais $(0-20 \mathrm{~cm}$ de profundidade) de um Latossolo Vermelho-Escuro fase cerrado e de um Cambissolo fase campo cerrado da zona fisiográfica Campos das Vertentes, MG. Cada solo foi submetido a três incubações seqüenciais: $\mathrm{CaCO}_{3}+\mathrm{MgCO}_{3}$ para manter o $\mathrm{pH}$ em torno de 6 , fertilização básica, incluindo o $\mathrm{P}$ em dose única, para manter $0,2 \mathrm{mg} \mathrm{L}^{-1}$ de $\mathrm{P}$ em solução e seis doses de $\mathrm{Si}\left(\mathrm{CaSiO}_{3}\right)$ definidas com base na dose de P. Foram avaliados a produção de matéria seca da parte aérea (MSPA), conteúdo de P e Si na MSPA e frações fosfatadas e fosfatase ácida em folhas apicais aos 60,90 e 120 dias após o transplantio das mudas para os vasos. Ajustaram-se superfícies de resposta para essas variáveis em razão das doses de Si e das épocas. Mudas cultivadas no Cambissolo tiveram ganho de 15,25\% no conteúdo de $\mathrm{P}$ na MSPA. Frações fosfatadas e atividade da fosfatase ácida em plantas não mostraram sensibilidade para avaliar a interação Si-P nos dois solos.
\end{abstract}

Termos para indexação: Eucalyptus grandis, absorção de nutrientes, metabolismo de minerais, conteúdo da matéria seca.

Silicon-phosphorus interactions in soils cultivated with eucalyptus under greenhouse conditions

\begin{abstract}
This experiment had the objective of evaluating the P-Si interactions in two soils by nutritional parameters of $\mathrm{P}$ in Eucalyptus grandis cuttings under effect of $\mathrm{Si}$ application. Two experiments were conducted in greenhouse conditions utilizing the surface layers $(0-20 \mathrm{~cm}$ in depth) of Dark-Red Latosol cerrado phase and of Cambisol campo cerrado phase of the physiographic zone Campos das Vertentes, $\mathrm{MG}$, Brazil. Each soil was submitted to three sequential incubations: $\mathrm{CaCO}_{3}+\mathrm{MgCO}_{3}$ p.a. to keep $\mathrm{pH}$ around 6.0; basic fertilization, including $\mathrm{P}$ in a single dose calculated to maintain $0.2 \mathrm{mg} \mathrm{L}^{-1}$ of $\mathrm{P}$ in solution; and six doses of $\mathrm{Si}\left(\mathrm{CaSiO}_{3}\right)$ defined on the basis of the dose of $\mathrm{P}$. The production of dry matter of the aerial part (DMAP), contents of $\mathrm{P}$ and $\mathrm{Si}$ in the DMAP and phosphate fractions and acid phosphatase activity in plants were evaluated at 60,90 and 120 days after the transplanting of cuttings to the pots. Multiple regression equations of these variables were adjusted in terms of doses of $\mathrm{Si}$ and of the evaluation times. Cuttings cultivated in the Cambisol presented gain of $15.25 \%$ in contents of $\mathrm{P}$ in the DMAP. Phosphorus fractions and acid phosphatase activity were not sensible to evaluate Si-P interaction at soils studied.
\end{abstract}

Index terms: Eucalyptus grandis, nutrient uptake, mineral metabolism, dry matter content.

(1) Aceito para publicação em 9 de junho de 2000

(2) Universidade Federal de Lavras (UFLA), Dep. de Química, Caixa Postal 37, CEP 37200-000 Lavras, MG. E-mail: dqi@ufla.br

(3)UFLA, Dep. de Ciência do Solo. E-mail: afurtini@ufla.br, niltcuri@ufla.br

(4) Universidade Federal de Minas Gerais (UFMG), Núcleo de Ciências Agrárias, Caixa Postal 135, CEP 39404-006 Montes Claros, MG. E-mail: lafernand@ig.com.br

(5)UFLA, Curso de Agronomia.

\section{Introdução}

Os primeiros trabalhos sobre absorção de silício (Si) e fósforo $(\mathrm{P})$ em solos datam do final da década de 1920, já havendo, portanto, consenso sobre alguns aspectos envolvidos na dinâmica dos dois elementos no solo: (a) fosfato e silicato são retidos (adsorvidos) pelos óxidos de ferro e de alumínio da fração argila, podendo assim competir entre si pelos 
mesmos sítios de adsorção, ou seja, silicato pode deslocar fosfato previamente adsorvido, e vice-versa, das superfícies oxídicas (Obihara \& Russel, 1972; Oliveira, 1984; Leite, 1997); (b) a aplicação de silicato finamente moído (escórias) antes da fosfatagem em solos cultivados com plantas acumuladoras de Si é prática comercial em diversas partes do mundo visando, entre outros benefícios, a correção de acidez (elevação de pH) e a competição Si x P no solo para melhorar a disponibilidade de $\mathrm{P}$ às plantas (Roy et al., 1971; Tisdale et al., 1985); (c) aplicações de silicato após a fosfatagem em condições de laboratório (Oliveira, 1984; Leite, 1997) ou de casa de vegetação permitem isolar o "efeito competição" do "efeito pH" desde que este último permaneça constante durante a fase experimental e que a planta indicadora utilizada não seja acumuladora de Si (Carvalho et al., 2000). Há evidências de que um vegetal só acumula Si por necessidade metabólica ou nutricional (Emadian \& Newton, 1989; Belanger et al., 1995) e, neste caso, o benefício do P dessorvido no solo pelo Si poderia confundir-se na planta com um provável efeito nutricional do Si acumulado.

A disponibilidade do $\mathrm{P}$ do solo pode afetar a sua distribuição nos compartimentos das plantas, entre os quais o P se movimenta: o apoplasto externo, em contato com a solução do solo, o apoplasto interno, em contato com o corpo principal da planta, o citoplasma ou espaço metabólico e o espaço vacuolar ou não-metabólico, delimitado pelo tonoplasto (Bieleski \& Ferguson, 1983). A dinâmica das frações de $\mathrm{P}$ na planta está relacionada com a atividade de fosfatases. À medida que diminui o fornecimento de $\mathrm{P}$ para as plantas, ocorre um aumento da atividade dessas enzimas de modo a converter o $\mathrm{P}$ vacuolar $(\mathrm{P}$ inorgânico - Pi) em P citoplasmático (P orgânico Po) (Bieleski \& Ferguson, 1983; Fernandes et al., 1998; Furtini Neto et al., 1998). Neste caso, as refinadas técnicas de medição do $\mathrm{P}$ de reserva, acumulado nos vacúolos $(\mathrm{Pi})$, e de sua transformação $(\mathrm{Po})$ por ação enzimática (fosfatases), apresentam-se como parâmetros promissores de avaliação em plantas do $\mathrm{P}$ dessorvido do solo por $\mathrm{Si}$.

O objetivo deste trabalho foi avaliar as interações Si-P em dois tipos de solos, por intermédio do estado nutricional de $\mathrm{P}$ em mudas de eucalipto sob efeito da aplicação do Si.

\section{Material e Métodos}

Amostras de um Latossolo Vermelho-Escuro (LE) fase cerrado e de um Cambissolo (C) fase campo cerrado, originados de rochas pelíticas pobres do Município de São Sebastião da Vitória, zona fisiográfica Campo das Vertentes, Minas Gerais, sob pastagem nativa, foram coletadas na camada 0-20 $\mathrm{cm}$ de profundidade. Os solos foram escolhidos por apresentarem expressiva representatividade territorial no País (Resende et al., 1997), teores semelhantes de argila e óxidos de ferro totais e diferentes teores de caulinita e gibbsita.

Os experimentos foram conduzidos em casa de vegetação no Departamento de Ciência do Solo da Universidade Federal de Lavras, MG. A unidade experimental constou de um vaso de plástico com capacidade para $3 \mathrm{dm}^{3}$, preenchido com $2,7 \mathrm{dm}^{3}$ de solo passado em peneira de $2 \mathrm{~mm}$ de diâmetro. Todos os vasos foram submetidos a três incubações seqüenciais por um período de 30 dias cada uma, sob condição de umidade equivalente a $60 \%$ do volume total de poros, controlada por pesagem diária. A primeira, com a mistura $\mathrm{CaCO}_{3}+\mathrm{MgCO}_{3}$ p.a., em quantidades definidas com base em experimento prévio de incubação, objetivou manter em $4: 1$ a relação $\mathrm{Ca}: \mathrm{Mg}$ e o $\mathrm{pH}$ em torno de 6. A segunda (fertilização básica), idêntica nos dois solos, à exceção do $\mathrm{P}$, correspondeu aos seguintes teores de nutrientes na forma de sais p.a. por $\mathrm{dm}^{3}$ (modificada de Malavolta et al., 1989): $80 \mathrm{mg}$ de $\mathrm{N}, 150 \mathrm{mg}$ de $\mathrm{K}, 40 \mathrm{mg}$ de $\mathrm{S}, 0,81 \mathrm{mg}$ de $\mathrm{B}, 3,6 \mathrm{mg}$ de $\mathrm{Mn}, 1,3 \mathrm{mg}$ de $\mathrm{Cu}, 1,6 \mathrm{mg}$ de Fe, $0,15 \mathrm{mg}$ de Mo e $5 \mathrm{mg}$ de $\mathrm{Zn}$. O Latossolo recebeu $225 \mathrm{mg} \mathrm{dm}^{-3}$ de $\mathrm{P}$ e o Cambissolo, $150 \mathrm{mg} \mathrm{dm}^{-3}$ de $\mathrm{P}$, doses únicas deduzidas de experimento prévio para determinação da capacidade máxima de adsorção de $\mathrm{P}$ e suficientes para manter $0,2 \mathrm{mg} \mathrm{L}^{-1}$ de $\mathrm{P}$.

A terceira incubação constou de seis doses de Si na forma de $\mathrm{CaSiO}_{3}$ (silicato de cálcio; $28,97 \%$ de Si e 13,21\% de Ca). No Latossolo, as doses foram 0, 112, 170, 225 , 280 e $340 \mathrm{mg} \mathrm{dm}^{-3}$ de Si e, para o Cambissolo, 0, 75, 112, 150,187 e $225 \mathrm{mg} \mathrm{dm}^{-3}$ de Si. Em cada solo, uma das doses foi numericamente idêntica à dose de $\mathrm{P}$ aplicada na segunda incubação. As demais corresponderam, nos seus extremos inferior e superior, a $50 \%$ da dose de P. Como a fonte de $\mathrm{Si}$ empregada trouxe o $\mathrm{Ca}^{2+}$ como cátion acompanhante, procedeu-se ao nivelamento do mesmo com $\mathrm{CaCO}_{3}$ p.a. nos tratamentos afins. Os resultados da análise química realizada depois de concluídas as três incubações (Tabela 1) revelam o nivelamento a que foram submetidos todos os parâmetros do complexo sortivo, à exceção do Si. Este, em sua forma solúvel em água $\left(\mathrm{H}_{4} \mathrm{SiO}_{4}\right)$, aumentou linearmente com as doses aplicadas. 


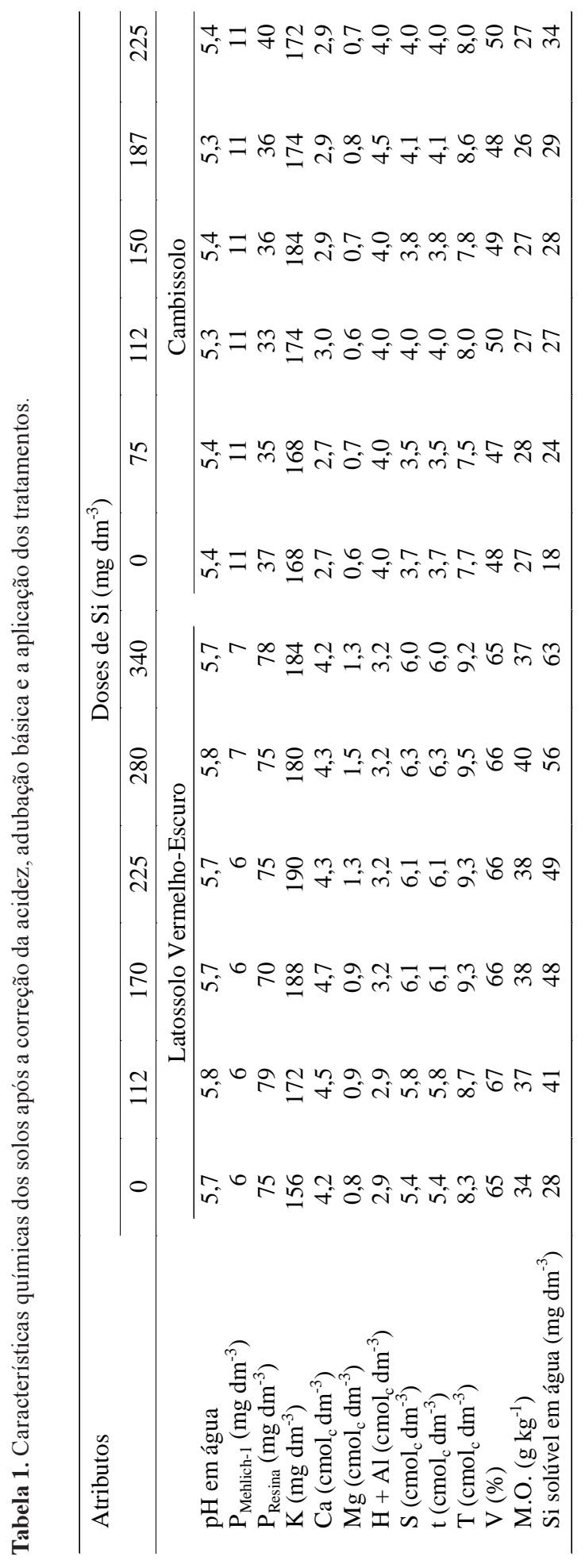

Decorridos 30 dias da última incubação, foram transplantadas quatro mudas por vaso. O delineamento experimental foi o inteiramente casualizado, arranjado num fatorial 6x3 (seis doses de Si e três épocas: 60, 90 e 120 dias após o transplantio das mudas) com quatro repetições, perfazendo 72 vasos por experimento (um solo por experimento), totalizando 144 vasos nos dois experimentos.

Aos 60, 90 e 120 dias após o transplante das mudas, as plantas foram colhidas, separadas em parte aérea e sistema radicular, secadas em estufa $\left(65-70^{\circ} \mathrm{C}\right)$, pesadas e moídas, sendo o P determinado após digestão nitroperclórica, conforme Malavolta et al. (1989), e em seguida convertido para conteúdo de $\mathrm{P}$ na matéria seca, o mesmo acontecendo com o Si após incineração dos tecidos vegetais a $500^{\circ} \mathrm{C}$ e dissolução alcalina da sílica $\left(\mathrm{SiO}_{2}\right)$, de acordo com Gallo \& Furlani (1978). Nas mesmas épocas, em folhas apicais fisiologicamente maduras foram determinadas as frações de $\mathrm{P}$, conforme método descrito por Smille \& Krotkov (1960) e Hogue et al. (1970) modificado por Martinez (1992) e Furtini Neto et al. (1998), e a atividade in vitro da fosfatase ácida, segundo método proposto por Santos (1985).

Todas as determinações foram feitas eliminando-se uma "terça parte" de cada experimento (24 vasos) numa época de avaliação. Concluída a análise de variância, foram ajustadas superfícies de resposta para as variáveis experimentais (produção de matéria seca da parte aérea, conteúdos de P e Si na matéria seca e frações fosfatadas e atividade da fosfatase em folhas apicais) em razão das doses de Si e das épocas de avaliação.

\section{Resultados e Discussão}

A produção de matéria seca da parte aérea (MSPA) das plantas cultivadas no Latossolo Vermelho-Escuro (LE) e no Cambissolo (C) aumentou, respondendo a incrementos das doses de $\mathrm{Si}$ e das épocas de avaliação (sinal positivo dos termos "Si" e "E" dos polinômios na Figura 1). No solo C (Figura 1), a idêntica significância dos coeficientes de doses e épocas $(1 \%)$ permite assumir que, estatisticamente, neste solo, os dois fatores não diferiram entre si na produção da MSPA. Ao contrário, no solo LE, pode-se admitir que houve, embora discreta, uma diferença estatística mais favorável à época (1\%) que à dose $(5 \%)$. Este fato deve ser analisado com cuidado, dado o efeito do Si nas plantas. Em primeiro lugar, o elemento não é considerado essencial, mas útil aos vegetais, notadamente gramíneas (Marschner, 1995). Nestas admite-se, inclusive, uma função metabólica 
LE

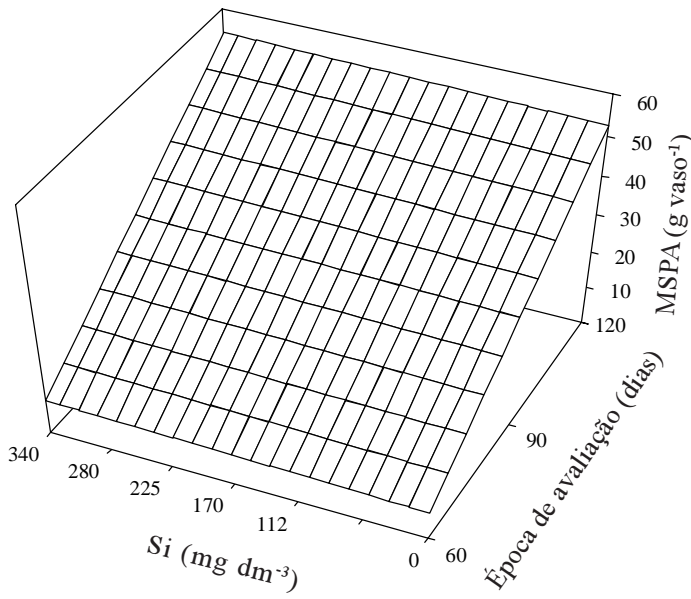

$\mathrm{Y}=-37,65+0,0055804 * \mathrm{Si}+0,751641 * * \mathrm{E}$ $\mathrm{R}^{2}=0,9793$

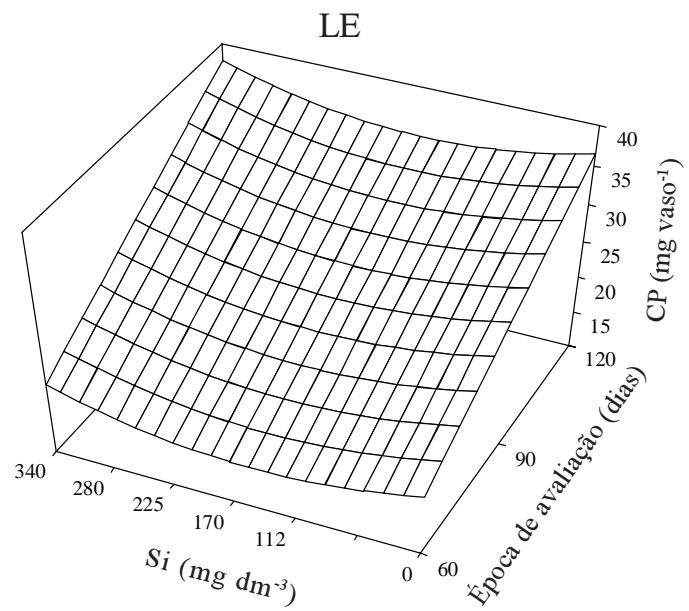

$\mathrm{Y}=0,50-0,0356685 * * \mathrm{Si}+0,0001185 * * \mathrm{Si}^{2}+0,300259 * * \mathrm{E}$ $\mathrm{R}^{2}=0,9312$

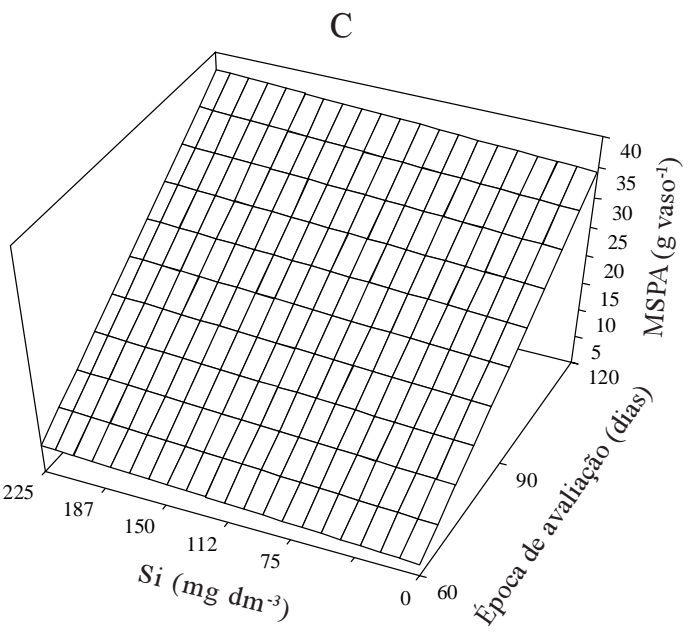

$\mathrm{Y}=-29,83+0,0131042 * * \mathrm{Si}+0,533924 * * \mathrm{E}$ $\mathrm{R}^{2}=0,9836$

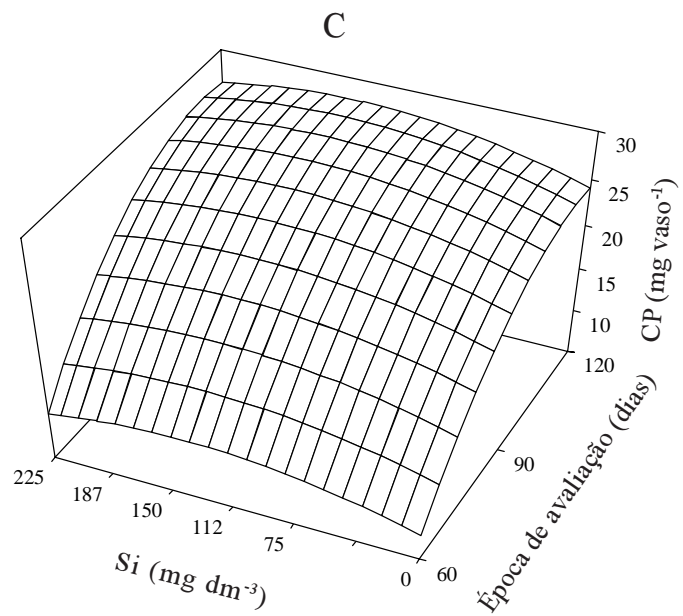

$\mathrm{Y}=-48,77+0,0529843 * \mathrm{Si}-0,0001891 * \mathrm{Si}^{2}+$ $1,28609 * * \mathrm{E}-0,0056576 * * \mathrm{E}^{2}$ $\mathrm{R}^{2}=0,9229$

Figura 1. Superfícies de resposta na produção de matéria seca da parte aérea (MSPA) e no conteúdo de $\mathrm{P}(\mathrm{CP})$ na matéria seca da parte aérea das plantas de Eucalyptus grandis cultivadas no Latossolo Vermelho-Escuro (LE) e Cambissolo (C), em razão das doses de Si e das épocas de avaliação. (* e **Significativo a $5 \%$ e $1 \%$ de probabilidade, respectivamente).

e portanto nutricional do $\mathrm{Si}$, ainda não relatada em relação à grande maioria das dicotiledôneas (nãoacumuladoras do elemento) (Emadian \& Newton, 1989; Belanger et al., 1995; Marschner, 1995) como é o caso do eucalipto. Além disso, o período de con- dução dos experimentos (120 dias) coincidiu com a época em que o eucalipto absorve $\mathrm{P}$ mais intensamente (Novais et al., 1990). Portanto, fatores outros que não o Si nas plantas devem estar também envolvidos na produção da MSPA. 
O sinal negativo do termo "Si" do polinômio na Figura 1 indica que, quanto maior a dose de Si aplicada, menor o conteúdo de $\mathrm{P}(\mathrm{CP})$ na matéria seca da parte aérea do eucalipto cultivado no LE. Fixando-se a época em 120 dias, por exemplo, e variando-se a dose de 0 (tratamento - controle sem adição de $\mathrm{Si}$ ) a $340 \mathrm{mg} \mathrm{dm}^{-3}$ de $\mathrm{Si}$, obtêm-se valores de CP respectivamente iguais a $36,34,34,34,36$ e $38 \mathrm{mg}_{\text {vaso }}^{-1}$, sendo o incremento observado a partir da dose de $170 \mathrm{mg} \mathrm{dm}^{-3}$ de $\mathrm{Si}$, graças à contribuição do termo "Si" (positivo). Derivando o polinômio, obtêm-se o ponto de mínimo desta superfície $\left(150 \mathrm{mg} \mathrm{dm}^{-3} \mathrm{de}\right.$ $\mathrm{Si})$ que, na referida época, corresponde ao menor valor de CP $\left(33,85 \mathrm{mg} \mathrm{vaso}^{-1}\right)$. Nota-se, também, que o $\mathrm{CP}$ referente ao tratamento-controle superou todos os demais, à exceção do valor $38,10 \mathrm{mg} \mathrm{vaso}^{-1}$; entretanto, neste caso, o ganho em $\mathrm{P}$ foi muito discreto $\left(1,57 \mathrm{mg} \mathrm{vaso}^{-1}\right)$. Variando-se as épocas $(60,90 \mathrm{e}$ 120 dias) dentro da dose $340 \mathrm{mg} \mathrm{dm}^{-3} \mathrm{de} \mathrm{Si}$, os valores de CP foram, respectivamente, iguais a 20, 29 e $38 \mathrm{mg} \mathrm{vaso}^{-1}$, um crescimento linear coerente com o sinal positivo do termo "E" do polinômio. Percebese, portanto, que o comportamento do $\mathrm{CP}$ foi melhor explicado pelo fator época do que pelo fator dose.

O sinal positivo dos termos lineares "Si" e "E" do polinômio na Figura 1 indica que o $\mathrm{CP}$ na matéria seca da parte aérea das plantas cultivadas no solo $\mathrm{C}$ aumenta, respondendo a incrementos tanto de doses quanto de épocas. O maior valor $\left(28,03 \mathrm{mg}\right.$ vaso $^{-1} \mathrm{de}$ P) foi obtido aos 113 dias com a dose de $140 \mathrm{mg} \mathrm{dm}^{-3}$ de $\mathrm{Si}$ (pontos de máximo obtidos da derivação do polinômio). A partir desses pontos, quaisquer aumentos de doses e de épocas, influenciados pelos termos "Si ${ }^{2 "}$ e "E $\mathrm{E}^{2 "}$ (positivos), provocam reduções no $\mathrm{CP}$. Ao contrário do LE, neste caso, o sinal positivo dos termos lineares, bem como sua idêntica significância (1\%), permitem inferir que não há diferença entre os fatores dose e época, em sua capacidade de influenciar o CP. Do polinômio da Figural se deduz, ainda, que o CP nas plantas do tratamentocontrole (sem adição de $\mathrm{Si}$ ), aos 113 dias, foi de $24,32 \mathrm{mg} \mathrm{vaso}^{-1}$ e que o diferencial entre os dois valores, $3,71 \mathrm{mg}$ vaso $^{-1}$, representou um ganho de $15,25 \%$ em P.

Como algumas características dos dois solos foram niveladas (Tabela 1), permanecendo como variáveis somente as doses de Si aplicadas, é razoável admitir que no Cambissolo uma fração do Si aplicado migrou para as superfícies oxídicas da fração argila, onde foi adsorvida. Esta adsorção provocou dessorção de parte do $\mathrm{P}$, que foi absorvido pelas plantas, conforme mostrado pelos dois pontos de máximo da Figura 1d. No Latossolo Vermelho-Escuro, ao contrário, o que ocorreu foi um ponto de mínimo para o CP (Figura 1), pressupondo, portanto, não ter havido dessorção de $\mathrm{P}$ por Si neste caso. O porcentual de P dessorvido por Si no Cambissolo (15,25\%) pode ser considerado de pequena magnitude, quando comparado com os valores encontrados por Roy et al. (1971), que foram de $47 \%$ em solos cauliníticos, e de $9 \%$ em solos gibbsíticos. Também no presente trabalho não se observou aumento no $\mathrm{CP}$ na matéria seca da parte aérea das plantas cultivadas no LE, solo que apresenta elevados teores de gibbsita. Esse aumento $(15,25 \%)$ do $\mathrm{P}$ acumulado provavelmente explica o ganho discreto na produção de MSPA das plantas cultivadas no $\mathrm{C}$ (Figura 1) detectado pela superfície de resposta.

Em ambos os solos utilizados parece razoável descartar o Si absorvido pelas plantas como o responsável pela produção de MSPA, apesar de o eucalipto mostrar-se responsivo ao elemento. No LE (Figura 2), o conteúdo de Si das plantas aumenta em razão de incrementos lineares das doses (sinal positivo do termo "Si") e diminui em razão de aumentos quadráticos das épocas (sinal negativo do termo " $\mathrm{E}$ " e positivo do termo

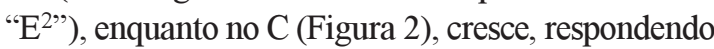
a incrementos lineares das doses e quadrático das épocas. Tomando-se como exemplo o maior valor encontrado no conteúdo de Si na MSPA de plantas cultivadas no LE, 14,66 mg vaso ${ }^{-1}$ de $\mathrm{Si}\left(31,37 \mathrm{mg} \mathrm{vaso}^{-1} \mathrm{de}\right.$ $\mathrm{SiO}_{2}$ ), e convertendo-o para porcentagem de $\mathrm{SiO}_{2} \mathrm{em}$ 9,31 g de MSPA, obtém-se $0,34 \%$ de $\mathrm{SiO}_{2}$. De acordo com Marschner (1995), classifica-se como nãoacumuladora qualquer planta que apresente conteúdo de $\mathrm{Si}$ inferior a $0,5 \%$ de $\mathrm{SiO}_{2}$. Por outro lado, plantas dicotiledôneas (não-acumuladoras, como o eucalipto) possuem um mecanismo que evita a absorção de quantidades elevadas do elemento (Jones \& Handrek, 1967). Pressupõe-se, portanto, ser diminuto ou até inexistente o papel metabólico do Si no eucalipto o que, aparentemente, o desqualifica como responsável pela produção de MSPA das plantas. 
R. Carvalho et al.

LE

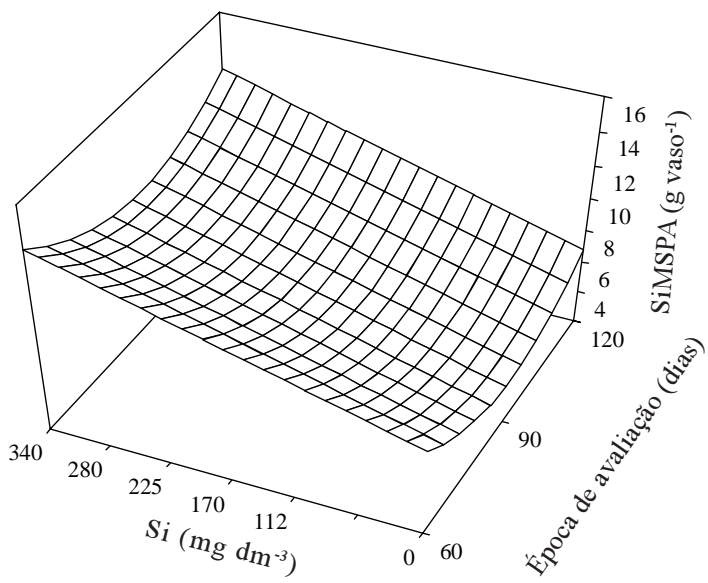

$\mathrm{Y}=30,21+0,0177555 * * \mathrm{Si}-0,561131 * * \mathrm{E}+0,0030488 * * \mathrm{E}^{2}$ $\mathrm{R}^{2}=0,7934$

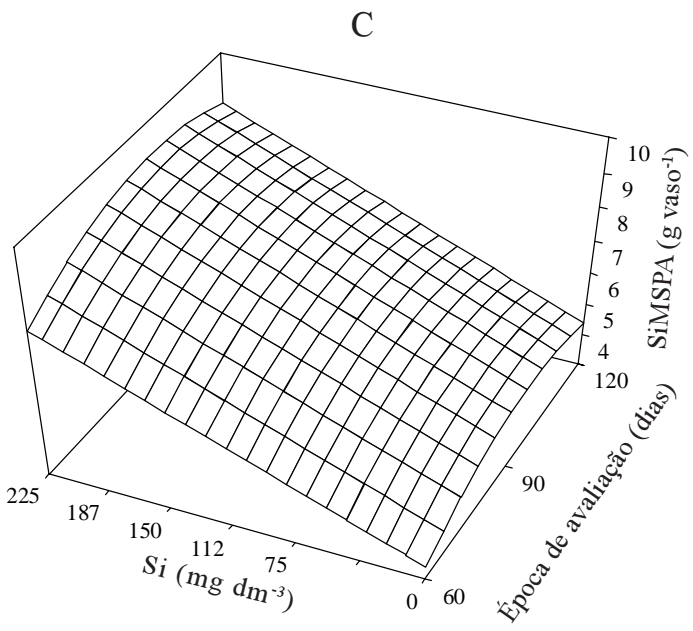

$\mathrm{Y}=-58,70+0,018889 * * \mathrm{Si}+0,198975 * * \mathrm{E}-0,0010161 * * \mathrm{E}^{2}$ $\mathrm{R}^{2}=0,7863$

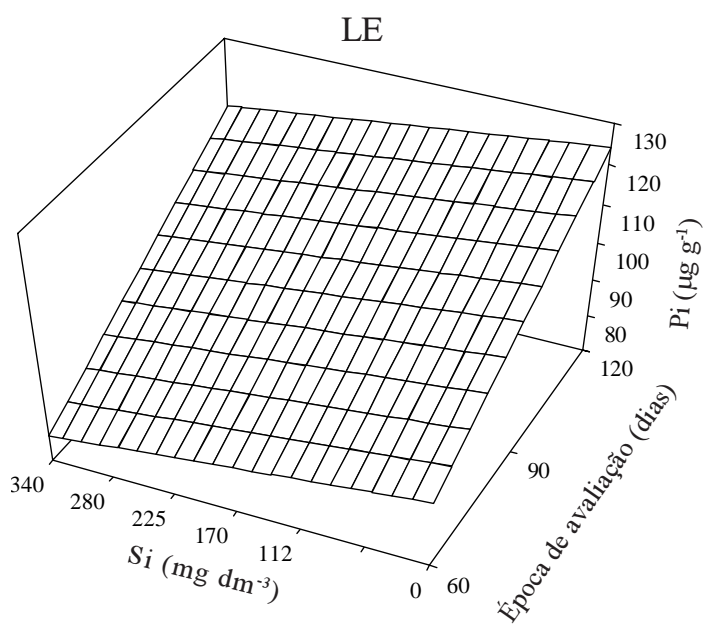

$\mathrm{Y}=51,88-0,03249 * * \mathrm{Si}+0,603315 * * \mathrm{E}$ $\mathrm{R}^{2}=0,7646$

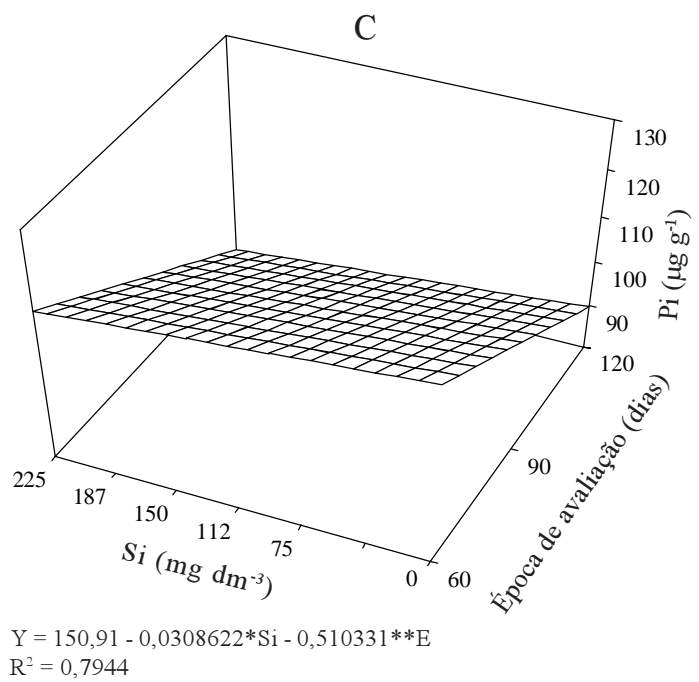

Figura 2. Superfícies de resposta no conteúdo de silício da matéria seca da parte aérea (SiMSPA) e no teor de fósforo inorgânico (Pi) em folhas apicais das plantas de Eucalyptus grandis cultivadas no Latossolo Vermelho-Escuro (LE) e no Cambissolo (C), em razão das doses de Si e das épocas de avaliação. (* e **Significativo a $5 \%$ e $1 \%$ de probabilidade, respectivamente).

O teor de fósforo inorgânico $(\mathrm{Pi})$ em folhas apicais das plantas cultivadas no LE diminui de forma linear em razão do aumento da dose de Si no solo (Figura 2). Já o Pi do eucalipto cultivado no $\mathrm{C}$ diminui linearmente, respondendo a aumentos, tanto de dose de Si quanto de época.
O teor de fósforo orgânico (Po) em folhas apicais do eucalipto cultivado no LE aumenta linearmente com a época e a dose (Figura 3).

Embora a análise de variância tenha detectado significância nas interações entre doses de Si e épocas de avaliação nas frações de $\mathrm{P}$ (à exceção do $\mathrm{Pt}_{\mathrm{s}}$ ) 


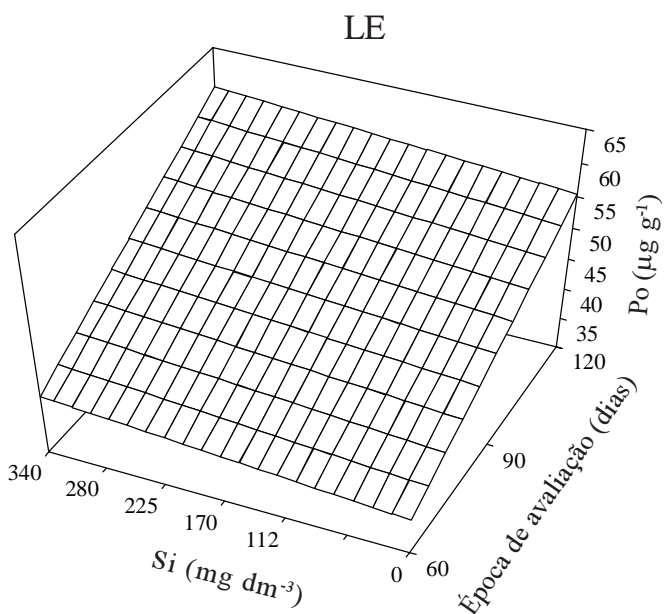

$\mathrm{Y}=16,35+0,0116296 * \mathrm{Si}+0,325049 * * \mathrm{E}$ $\mathrm{R}^{2}=0,6227$

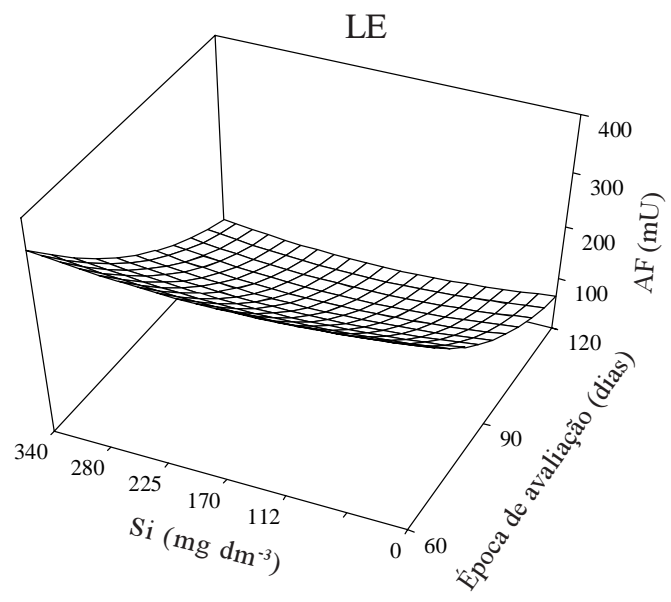

$\mathrm{Y}=973,96-0,287448 * \mathrm{Si}+0,0007835 * \mathrm{Si}^{2}-13,1077 * * \mathrm{E}+0,0461784 * * \mathrm{E}^{2}$ $\mathrm{R}^{2}=0,9260$

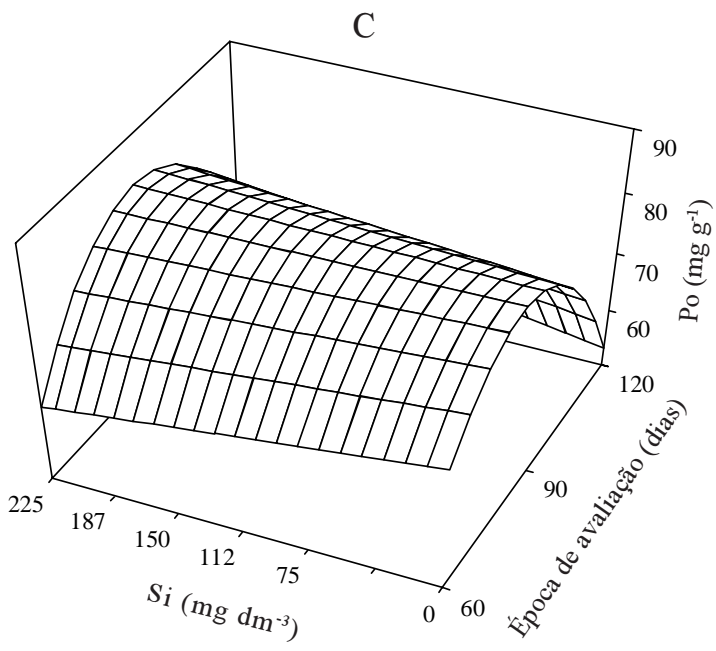

$\mathrm{Y}=-62,91-0,121873 * * \mathrm{Si}+3,51208 * * \mathrm{E}-0,0212126 * * \mathrm{E}^{2}+0,00141204 * * \mathrm{SiE}$ $\mathrm{R}^{2}=0,7314$

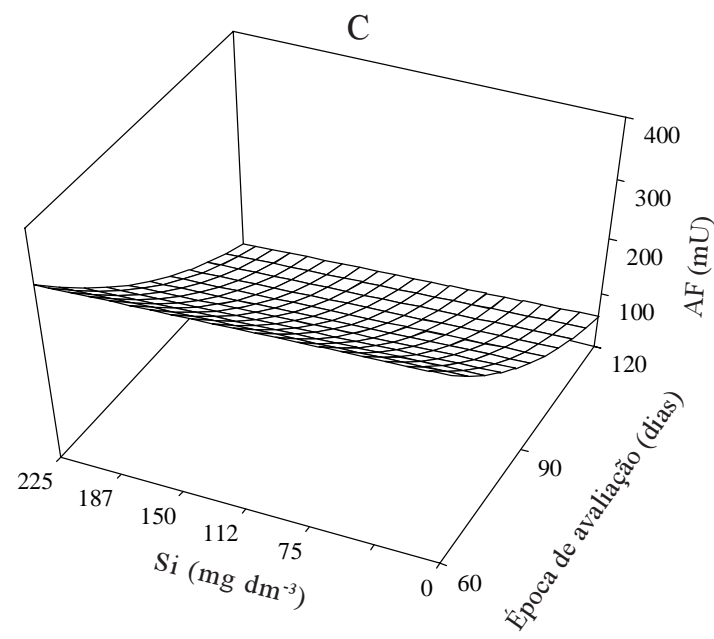

$\mathrm{Y}=894,35-0,117777 * \mathrm{Si}-116223 * * \mathrm{E}+0,0387762 * * \mathrm{E}^{2}$ $\mathrm{R}^{2}=0,9072$

Figura 3. Superfície de resposta no teor de fósforo orgânico (Po) e na atividade da fosfatase (AF) em folhas apicais das plantas de Eucalyptus grandis cultivadas no Latossolo Vermelho-Escuro (LE) e no Cambissolo (C), em razão das doses de $\mathrm{Si}$ e das épocas de avaliação. (* e **Significativo a 5\% e 1\% pelo teste de $\mathrm{t}$, respectivamente).

em folhas apicais do eucalipto, a visualização do fenômeno através das superfícies de resposta indica, de modo geral, tratar-se de um efeito que pode ser atribuído mais às épocas do que às doses. Conforme demonstrado por Fernandes et al. (1998), em feijoeiro, e Furtini Neto et al. (1998), em eucalipto, as oscilações de $\mathrm{Pt}_{\mathrm{s}}$, Pi e Po manifestaram-se de forma mais nítida quando as plantas foram cultivadas sob condições de estresse induzido por omissão de $\mathrm{P}$ no solo ou em solução nutritiva.

Pelos resultados obtidos no presente trabalho, pode-se fazer duas inferências: a) durante os 120 dias 
de condução dos experimentos, não houve estresse de $\mathrm{P}$ nos solos que pudesse comprometer o desenvolvimento normal das plantas, mesmo numa fase vegetativa de intensa absorção de $\mathrm{P}$, conforme Novais et al. (1990), já que o eucalipto absorveu porcentuais muito reduzidos do total aplicado nos vasos; $b$ ) as doses de $\mathrm{P}$ aplicadas, consideradas baixas durante a fase de planejamento experimental, em razão das elevadas capacidades máximas de adsorção de $\mathrm{P}$ (1.666 $\mathrm{g} \mathrm{kg}^{-1}$ no LE e $1.380 \mathrm{~g} \mathrm{~kg}^{-1}$ no C) dos solos, mostraram-se na realidade altas o suficiente para manter níveis elevados do nutriente nos solos e nas plantas, não justificando, portanto, transformações significativas do $\mathrm{P}$ vacuolar ou de reserva $(\mathrm{Pi}) \mathrm{da}$ planta em $\mathrm{P}$ citoplasmático ou metabólico $(\mathrm{Po})$.

A atividade da fosfatase nas plantas de eucalipto cultivadas no LE diminuiu à medida que aumentaram as doses de Si no solo e as épocas de avaliação (Figura 3c). Essa queda de atividade deve-se muito mais às épocas do que às doses, além de ter havido maior significância estatística em relação à época $(1 \%)$ do que em relação à dose $(5 \%)$. No solo $\mathrm{C}$ (Figura 3), o comportamento da enzima foi semelhante, mas sem contribuição quadrática das doses $\left(\mathrm{Si}^{2}\right)$. Neste caso, o fator época também com maior significância estatística $(1 \%)$ do que o fator dose $(5 \%)$, teve um papel mais destacado em reduzir a atividade enzimática.

O comportamento da fosfatase, de acordo com Bieleski \& Ferguson (1983) e Fernandes et al. (1998), influi na dinâmica das frações fosfatadas na planta, $\mathrm{e}$ assim menor disponibilidade de P no solo ou em solução nutritiva provoca aumento da atividade enzimática, necessária para converter o $\mathrm{P}$ vacuolar ou de reserva (Pi) em P citoplasmático ou metabólico (Po). Como a redução da atividade coincidiu com a ausência de estresse do nutriente nos solos e nas plantas, conforme os cálculos realizados durante a explicação das oscilações das frações fosfatadas, este fato confirma não ter havido necessidade de converter Pi em Po por ação enzimática, e concorda também com observações de Fernandez \& Ascencio (1994). Segundo esses autores, a fosfatase não foi um bom indicador do estresse de $\mathrm{P}$ em plantas com deficiência moderada do nutriente, e a queda verificada na atividade enzimática foi decorrente do tempo, de acordo, portanto, com os resultados obtidos neste trabalho.

\section{Conclusões}

1. O ganho em fósforo, de pequena magnitude, é responsável pelo incremento também discreto da produção de matéria seca das plantas de eucalipto cultivadas no Cambissolo.

2. A ação do silício na dessorção de fósforo é mais evidente no solo menos intemperizado, com maior teor de caulinita (Cambissolo) do que no solo mais intemperizado, com maior teor de gibbsita (Latossolo).

3. Em solos onde não existe estresse de fósforo, as frações fosfatadas e a atividade da fosfatase em plantas não mostram sensibilidade suficiente para detectar reduzidos porcentuais de fósforo dessorvido por silício.

4. O conteúdo de fósforo na matéria seca é um parâmetro eficiente de avaliação indireta da dessorção de $\mathrm{P}$ por $\mathrm{Si}$

\section{Referências}

BELANGER, R. R.; BOWEN, P. A.; EHRET, D. L.; MENZIES, J. G. Soluble silicon, its role in the crop and disease management of greenhouse crops. Plant Disease, St. Paul, v. 74, n. 4, p. 329-336, 1995.

BIELESKI, R. L.; FERGUSON, I. B. Physiology and metabolism of phosphate and its compounds. In: LAUCHLI, A.; BIELESKI, R. L. (Ed.). Encyclopedia of plants physiology: inorganic plant nutrition. Berlin : Springer, 1983. p. 422-429.

CARVALHO, R.; FURTINI NETO, A. E.; CURI, N.; FERNANDES, L. A.; OLIVEIRA JUNIOR, A. C. Dessorção de fósforo por silício em solos cultivados com eucalipto. Revista Brasileira de Ciência do Solo, Viçosa, v. 24, p. 69-74, 2000.

EMADIAN, S. F.; NEWTON, R. J. Growth enhancement of loblolly pine (Pinus taeda L.) seedings by silicon. Journal of Plant Physiology, Jena, v. 134, p. 98-103, 1989.

FERNANDES, L. A.; FURTINI NETO,A. E.; CURI, N.; GUEDES, G. A. A.; LIMA, J. M. Fósforo e atividade da fosfatase ácida em plantas de feijoeiro. Pesquisa Agropecuária Brasileira, Brasília, v. 35, n. 5, p. 769-778, maio 1998

FERNANDEZ, D. S.; ASCENCIO, J. Acid phosphatase activity in bean and cowpea grown under phosphorus stress. Journal of Plant Nutrition, New York, v. 15, n. 2/3, p. 229-241, 1994 
FURTINI NETO, A. E.; BARROS, N. F.; NOVAIS, R. F.; OLIVEIRA, M. F. G. Frações fosfatadas em mudas de Eucalyptus. Revista Brasileira de Ciência do Solo, Viçosa, v. 22, n. 2, p. 267-274, 1998

GALLO, J. R.; FURLANI, P. R. Determinação de silício em material vegetal pelo método colorimétrico do azul de molibdênio. Bragantia, Campinas, v. 37, n. 2, p . 5-11, 1978.

HOGUE, E.; WILCOX, G. E.; CANTILIFFE, D. J. Effect of soil phosphorus levels on phosphate fractions in tomato leaves. American Society for Horticultural Science Journal, Alexandria, v. 95, p. 174-176, 1970.

JONES, L. H. P.; HANDREK, K. A. Silica in soil, plants and animals. Advances in Agronomy, San Diego, v. 19, p. $107-147,1967$.

LEITE, P. C. Interação silício-fósforo em Latossolo-Roxo cultivado com sorgo em casa-de-vegetação. Viçosa : UFV, 1997. 87 p. Tese de Doutorado

MALAVOLTA, E.; VITTI, G. C.; OLIVEIRA, S. A. Avaliação do estado nutricional das plantas: princípios e aplicações. Piracicaba : POTAFOS, 1989. 201 p.

MARSCHNER, H. Mineral nutrition of higher plants 2. ed. London : Academic, 1995. 889 p.

MARTINEZ, H. E. P. Cinética da absorção e das frações fosfatadas em sete variedades de soja (Glycine $\max$ L. Merril). Viçosa : UFV, 1992. Não paginado. Relatório final de programa de pós-graduação.
NOVAIS, R. F.; BARROS, N. F; NEVES, J. C. L. Nutrição mineral do eucalipto. In: BARROS, N. F.; NOVAIS, N. F. (Ed.). Relação solo-eucalipto. Viçosa : UFV, 1990. p. 25-98

OBIHARA, C. H.; RUSSEL, E. W. Specific adsorption of the silicate and phosphate by soils. Journal of Soil Science, Oxford, v. 23, p. 105-117, 1972.

OLIVEIRA, M. G. A. Determinação, adsorção e deslocamento recíproco de silício e fósforo em Latossolos do Triângulo Mineiro. Viçosa : UFV, 1984. 68 p. Dissertação de Mestrado.

RESENDE, M.; CURI, N.; RESENDE, S. B.; CORREA, G. F. Pedologia: base para distinção de ambientes. 2 .ed. Viçosa : UFV-NEPUT, 1997. 304 p.

ROY, A. C.;ALI, M. V.; FOX, R. L.; SILVA, J.A. Influence of calcium silicate on phosphate solubility and availability in Hawaiian latossols. In: SYMPOSIUM ON SOIL FERTILITY AND EVALUATION, 1971, Honolulu. Proceedings... New Delhi : University of Hawaii, 1971. p. $756-765$

SANTOS, C. D. Fisiologia e bioquímica da digestão em Erimis ello (Lepidoptera: Sphingidae). São Paulo : USP, 1985. 178 p. Tese de Doutorado.

SMILLE, R. M.; KROTKOV, F. The estimation of nucleic acids in some algae and higher plants. Canadian Journal of Botany, Ottawa, v. 38, p. 31-49, 1960.

TISDALE, S. L.; NELSON, W. L.; BEATON, D. J. Soil fertility and fertilizers. 4. ed. New York : MacMillan, 1985. $754 \mathrm{p}$ 